\title{
Seis tesis sobre los orígenes teológicos del poder
}

\section{Six thesis on the ideological origins of power}

\section{David Lagunas}

Universidad de Sevilla

dlagunas@us.es

\section{RESUMEN}

En este ensayo se plantea una reflexión acerca de los orígenes teológicos del poder. La relación entre la religión y el poder más obvia reside en los rituales políticos y en los religiosos. Sin embargo, la alianza entre ambas dimensiones de la cultura va más allá de esta semejanza formal y se extiende hacia varias dimensiones de la religión que reflejan una vinculación con el poder, lo cual me permite pensar heurísticamente sobre el fenómeno religioso.

\section{PALABRAS CLAVE}

Religión, poder, antropología

\section{ABSTRACT}

This essay offers a reflection on the theological origins of power. The relationship between religion and power most obvious lies in political rituals and religious rituals. However, the alliance between the two dimensions of culture goes beyond this formal similarity and extends to various dimensions of religion that reflect a relationship with power, which allows me to think about the religious phenomenon heuristically.

\section{KEYWORDS}

Religion, power, anthropology

1 David Lagunas Arias realizó sus estudios de licenciatura y doctorado en la Universitat de Barcelona. Es doctor en Humanidades. Actualmente es profesor titular en Antropología Social en la Universidad de Sevilla. Ha sido profesor en la Universidad Autónoma del Estado de Hidalgo y la Escuela Nacional de Antropología e Historia, en México. Es autor de más de un centenar de publicaciones. Sus temas de interés se orientan al estudio de minorías étnicas y sectores sociales excluidos, así como a modelos de investigación en ciencias sociales. Es miembro regular de la Academia Mexicana de Ciencias, México y de The European Academic Network on Romani Studies (Consejo de Europa), Estrasburgo. 


\section{Introducción}

Es un truismo señalar que el poder no es un concepto universal. En la ciencia occidental han habido desarrollos importantes del concepto $y, a$ pesar de que no siempre encaje en la aplicación a diversos temas de estudio, existe un consenso entre la comunidad científica a la hora de pensar el poder. Lo difícil, sin embargo, es que el concepto de poder posea testabilidad y validez objetiva. Para ello, se requiere de un mínimo analítico, es decir, una definición que sirva de punto de partida; por ejemplo, la siguiente: «el poder es la capacidad para conducir, alterar o anular las facultades humanas». En términos generales, el poder proviene de tres fuentes: la naturaleza, la sociedad y, de manera más directa, el poder ejercido por las propias personas. Implícitamente, esta definición apunta a que es necesario que exista una forma de control social permanente, es decir, que una persona controle en parte a otras. Esta relación de control ha de estar por encima de otras dimensiones de la sociedad, por ejemplo, del sistema de parentesco, a pesar de que Lévi-Strauss (1969) sostenga que el parentesco ya es político, puesto que es el principio de organización y articulación social de las sociedades tradicionales. Por tanto, es la obligatoriedad de aceptar un orden jerárquico, sus reglas y reconocer esta relación social lo transcendente en las definiciones sobre el poder. Una vez asumido esto, podemos hablar de una forma instituida a la que llamamos política y afirmar que la organización política de cualquier sociedad no es natural sino convencional.

Para los intereses de este texto, la tentativa es reflexionar sobre los orígenes teológicos del poder. Mi perspectiva se sitúa en la intersección entre la religión y la política, como ámbitos que se encuentran separados en nuestra sociedad, no así en otras sociedades. Es obvio que esta tentativa no es más que un artificio metodológico para articular convergencias del sentido en el momento de la investigación, la proximidad de formas, o para poner orden en las numerosas y microscópicas observaciones empíricas en unidades de comportamiento colectivos, advirtiendo que no existen tipos puros sino tipos ideales, a lo Weber (Tarrius, 2000), lo cual permite avanzar en el conocimiento de un tema.

Es importante advertir acerca de una premisa que no podemos soslayar. Siguiendo a Dumont (1970, pp. 3-4), la configuración moderna (occidental) de los valores se encuentra atomizada en el sentido de que se centra sobre el hombre «individual» y a la vez en la yuxtaposición de diferentes valores autónomos: religión, filosofía, política, economía, arte. Esto puede ser algo excepcional y de ninguna forma generalizable, puesto que en sociedades tradicionales (holísticas) la configuración de los valores tiene un carácter jerárquico, de forma que el marco normativo que 
convencionalmente llamamos religión organiza, limita y constriñe el reconocimiento de otras consideraciones sociales. Una consecuencia de ello es que la política no es una categoría universal ni tampoco una categoría susceptible de ser generalizada. Por otro lado, como dice Dumont, nuestras distinciones y concepciones de la religión y la política como ámbitos separados y separables no son operativas allí donde las fronteras entre ambas aparecen más borrosas, como es el caso de las instituciones políticas. Además, no cabe obviar los enfoques que parten de la premisa metodológica de que la religión puede ser una variable dependiente de la política y viceversa. Un ejemplo de lo primero serían los efectos políticos que las acciones (o inaniciones) de los gobiernos en México para implantar la ley del aborto provocan en las instituciones y grupos religiosos; ejemplo de lo segundo lo constituyen los grupos religiosos que pretenden obtener poder político, como los legionarios de Cristo en países latinoamericanos o el judaísmo ortodoxo en Israel.

Grosso modo, estas seis dimensiones que pretendo explorar se resumirían de la siguiente forma:

1. La religión concebida como actividad humana primordial, la más original, y la que define los umbrales de la cultura y el origen de la sociedad. Desde este enfoque, «el hombre sería hombre» a partir de manifestaciones mínimas de rituales y ceremonias.

2. La religión como proyección y mitificación social, es decir, como extensión del orden social. La religión constituiría un universo simbólico que ya existe en la sociedad convencional y mitificaría las relaciones sociales o las proyectaría. Desde este punto de vista, la religión perfecciona la sociedad simbólicamente o bien constituye un síntoma del estado de las relaciones sociales.

3. La religión como aparato ideológico, un instrumento manipulado desde el exterior y utilizado para que la gente piense y se comporte de determinada manera. Esta concepción coincidiría con la visión marxista.

4. La religión como lubricante social que agiliza los engranajes sociales. Se trataría de un sistema no demasiado estructurado, donde lo importante radicaría en su función cohesionadora, perspectiva que se inicia con Maquiavelo y que continúa Durkheim.

5. La religión como mito, a partir de considerar la lógica de los pueblos primitivos sumada a la lógica de nuestra civilización, a lo Lévi-Strauss. La religión sería pues una manera de pensar sobre una cosa (perspectiva cercana a la primera).

6. La religión como chamanismo, es decir, una actividad alternativa o un orden de reglas al margen del orden político.

Analizaremos, a continuación, cada una de estas dimensiones, teniendo como base los aportes y las contribuciones de las ciencias sociales y humanas. 


\section{Actividad humana primordial}

Desde esta perspectiva se plantea que la experiencia humana es tan singular que la primera respuesta humana es transcendente. Según esta idea, cuando el hombre se enfrenta a su medio natural y social tiene dificultades cognitivas, lo cual provoca una reacción de trascendencia primigenia y primordial. Puesto que esta situación es parte de una inadecuación e insatisfacción, se buscan cosas más allá de lo material para componer la realidad.

Así pues, se parte de la premisa de que el aprendizaje social supone una imitación, es decir, hacer alguna cosa no espontánea, una cosa exacta y reconocida en busca de un sentido, aprendiendo unos actos como hablar y sobrevivir, aunque el sentido que se extraiga de todo ello no sea exacto para todos los humanos. A partir de aquí, se puede afirmar en qué consiste la religión: hacer preguntas y construir realidades que no están dadas de antemano. Por ello, la religión no se reduce a una Iglesia ni a una jerarquía, ni tampoco constituye un fenómeno simbólico, sino más bien se trata de una manera de comportarse y de inquietarse frente a un mundo que no se entiende y unos comportamientos que el ser humano no cree seguros.

Lo importante en esta argumentación es que plantea que los primeros sentimientos del ser humano frente a la inadaptación son de inquietud e inseguridad. De aquí que se dirija hacia el ritual, los mitos y las ceremonias de las cosas de la vida. Ejemplo de ello son la muerte y el cambio de estatus como hechos dramáticos que suscitan conflictos e inadecuación. Para ello, el hombre generaría el lenguaje de las emociones religiosas a través de diversas mediaciones: 1) el ritual: reacción de dramatización personal o colectiva de fenómenos sin resolución (la pregunta sería: «¿qué hacer con los muertos?»); 2) el mito: explicación que permite pensar sobre estos fenómenos («¿cómo explicar la muerte?»); 3) la ceremonia²: frente a unos hechos actuamos según un comportamiento ceremonial, en ocasiones espontáneo, en otras elaborado; la ceremonia constituye la propia fuerza de la dramatización, aportando expresividad a la experiencia de una emoción, sentimiento o idea, aunado a que la ceremonia comporta ritual y viceversa; 4) la religión: los fenómenos religiosos suponen una discriminación con personas que conocen más o menos el tema religioso.

2 Zulaika (1992, p. 85) identifica las diferencias entre ritual y rito (sinónimo aquí de ceremonia): «no se debe ceñir la noción de rito a las ceremonias espectaculares; al contrario, algunas cosas solo se pueden manifestar por medio del ritual, y en ese sentido el ritual resulta ser la actividad social más fundamental y ordinaria. Se pueden diferenciar los ritos y el ritual: mientras que los primeros son acontecimientos caracterizados por su formalidad (las ceremonias sociales diarias, un juicio, la coronación del rey), el ritual es el aspecto formal invariable de todo acontecimiento». 
Dos representantes de esta perspectiva primordialista son Fustel de Coulanges y Ludwig Wittgenstein. Veámoslo con detalle.

Fustel de Coulanges (1983) se encamina a estudiar las raíces de las lenguas clásicas e indoeuropeas. Fustel afirma que los términos fundamentales para designar la autoridad y las relaciones familiares son de origen religioso, identificando en la lengua indoeuropea y clásica un radical previo que significa una divinidad y que evoluciona hacia el parentesco (padre, madre, etc.). El padre es el oficiante de un culto, un sacerdote; el hogar es el lugar de los dioses en los clásicos grecorromanos. Y todas estas - concluye- son experiencias religiosas. Así pues, las primeras palabras inventadas por el hombre lo fueron para designar elementos que no podía ver, es decir, fenómenos religiosos, de forma que el origen del lenguaje sería la propia religión. En consecuencia, cualquier orden es previo de la estadía de los dioses (idea platónica) y nuestro mundo sería una sombra de este mundo más perfecto que intuimos. Así, la ciencia y las matemáticas se acercan a este mundo, y la perfección más grande estaría en este mundo. Por tanto, cabría buscar perfecciones de nuestra experiencia (idea propia de la Antigüedad).

La interpretación de las religiones primitivas por parte de Frazer apunta a que esas formas religiosas implican inferioridad intelectual o un estadio previo de la ciencia, solucionando todo a través de la magia. Los «salvajes» pensaban y creían que podían variar el curso de las cosas ya que todavía no habían aprendido a pensar bien, de forma que su ciencia era una ciencia «bastarda» que funcionaba a trompicones, balbuceando. Esto es equivalente a argumentar que si una persona no puede obtener una cosa entonces llora, o cuando el adulto le dice al niño que llorar no tiene nada que ver con el objeto (el niño piensa que llorando lo obtendrá). Los pueblos primitivos han sido pensados en el pasado como niños que Iloran, los cuales ejecutando rituales (llorando) conseguirían la lluvia o el bienestar. Wittgenstein (1992) afirma lo contrario: cuando un niño llora no es porque quiera un juguete o influya en el adulto, sino que lo hace naturalmente, porque tiene ganas; la base de llorar es natural y será por motivos naturales que habrá gente que llorará o no llorará.

Según este enfoque, el ritual constituiría una reacción natural frente a algo natural, la magia sería un conjunto de reacciones naturales y la religión la articulación de unos rasgos naturales por dogmas y ceremonias. Dicho de otro modo, el hombre sería ceremonial en la manifestación de sus deseos y dada la indefinición de su comportamiento, el hombre iría reinventando sus formas de transcendencia. El impulso religioso existiría siempre, pero sería reconstruido continuamente. La conclusión es que la religión precedería a la política, la cual se expresaría en función de estas 
reacciones primordiales. Fustel defiende la religión natural, al igual que los ilustrados (Rousseau defendía el retorno a la religión natural en contra de las instituidas) o los románticos, argumentando que existen unas emociones humanas universales que tienen que ver con experiencias mínimas. Estas reacciones primordiales de carácter psicológico que el hombre ejerce de manera colectiva, estableciendo reglas y códigos, tendrían que ver con la política en dos aspectos:

a. Las instituciones religiosas alienan y monopolizan estos comportamientos fundamentales. Los humanos se ven obligados a realizar estas manifestaciones bajo un poder teocrático. Este sería el primer tipo de poder. La competencia por el poder religioso (las dramatizaciones de la vida) sería el origen de la política: la apropiación de sentimientos necesarios y de sus celebraciones colectivas (muerte, nacimiento, etc.). La política, en este sentido, constituiría la forma para controlar las emociones y celebraciones religiosas. No es casual que los evolucionistas del XIX señalaran a la teocracia como el origen de la humanidad, lo cual fue refutado por el marxismo y el liberalismo que planteaban que las disputas no son religiosas sino frente a los productos y las riquezas.

b. Si existieran estas reacciones naturales por su inadaptación y si, además, existe una institución social que las monopoliza, de ello se infiere que se produce una alienación religiosa. Se trataría de la institucionalización de las relaciones religiosas, de forma que el lugar y el templo de las celebraciones es un espacio controlado socialmente. Por tanto, estas reacciones no son naturales sino que tienen sentido dentro del templo. Una vez que la religión aliena estas relaciones, la religión se extiende y acapara las conciencias pero en realidad se ejerce menos puesto que hay normas institucionales. El poder, entonces, jugaría con el extrañamiento de los sentimientos religiosos y su materialización en un tiempo y un espacio por una jerarquía religiosa y, por ello, se produciría una lucha por el control de las primeras expresiones humanas que engendrarían el poder político y religioso al mismo tiempo. Los líderes religiosos, que podrían coincidir con los chamanes, serían los que convencerían más por su carisma, proporcionando un patrón para expresar su piedad y sus sentimientos a través de mitos y rituales.

Una posición relevante al respecto es la crítica de Asad (1993) hacia Geertz, a quien reclama su idea acerca de un modelo «de» cultura como texto y la religión como esencialmente cognitiva, definida así como un sistema de símbolos exportable para todo tiempo y lugar. Asad (1993, p. 29) señala que este planteamiento cae en el error de separar religión y política afirmando en relación con el cristianismo medieval y el islam histórico, que no son los símbolos los que determinan las disposiciones 
reales, sino el poder, el cual se despliega en leyes, conceptos de pecado, escuelas, y otras actividades disciplinarias. En ambos casos, religión y poder son intrínsecos. En suma, es la idea de poder y control, y no la idea culturalista de significado y creencia, la que permite pensar la religión y sus fundamentos de autoridad.

\section{Proyección del orden social}

Desde esta perspectiva, la religión no existe desde el comienzo, sino que lo original es la vida social, el trabajo, la adaptación al medio y la vida material. La religión viene después como una proyección ideal de la propia sociedad y nos habla de una sociedad ideal, es decir, la religión idealiza la sociedad que hemos construido y sirve para actuar en la sociedad como ideal de moralidad y de construcción social. Por ello, puede ser una justificación (legitima la sociedad) o una mitificación (busca una nueva sociedad) del orden social, de forma que la religión se manifiesta como una respuesta sociológica. La masonería, por ejemplo, constituye una relación de proyección social pues se propone perfeccionar la sociedad mientras que el judaísmo por su lado refleja una relación de actuación en este mundo.

Si observamos este proceso en perspectiva histórica, los ejemplos son muy significativos. Por ejemplo, entre los esenios, secta judía anacoreta del siglo I antes de Cristo, se introduce el discurso escatológico iranio en la cultura hebraica, la repetición del mito final del Irán prezoroastro: llegará un día que resucitarán los muertos. Los cultos iranios escatológicos de la segunda venida influyen en la religiosidad mediterránea, introduciendo el apocalipsis que hará volver al mito inicial.

Esta dimensión también tiene que ver con las utopías. Bloch (1979) señalaba que las utopías religiosas tenían finalidades sociológicas. Los movimientos milenaristas afirman que la sociedad ideal es conducida por un líder o un pueblo. Ejemplo de ello en Melanesia son los «cultos del cargamento» donde los nativos creían a primeros de siglo XX que llegaría un barco cargado con sus antepasados quienes los liberarían de los colonizadores (Worsley, 1980). Los cultos del cargamento surgen entre los melanesios con la conciencia de la miseria e injustica tras el contacto con los blancos, lo cual les proporciona la posibilidad de idealizar un futuro, de que era posible la esperanza, al igual que los cristianos y el apocalipsis como salvación de la injusticia. Igualmente, el mito azteca de Quetzaltcoatl posee connotaciones apocalípticas con la llegada de un orden social nuevo.

A partir de que el hombre tiene conciencia de la injusticia nace el sentimiento quiliásmico. En los movimientos milenaritas existe la conciencia de que hay algo que se ha degradado, la vida social, y que tiene que purificarse por medio del «ángel exterminador» que puede ser uno mismo, 
rompiendo con el pasado. Los pueblos comparten el inconsciente, el alma y una razón común, poseen una memoria colectiva codificada en los mitos que explican sus orígenes. La aculturación de América significó la lobotomización de un sistema de creencias, dado que se acabó con una parte importante de la memoria de los pueblos quemando, fusilando. El milenarismo y el utopismo, por tanto, expresan la idealización del futuro. Este se basa en los mitos como máquinas de tratar el tiempo y de anularlo, a lo Lévi-Strauss. Mito e historia se intersectan como muestra Sahlins (1988) en el relato de la muerte del capitán Cook entre los hawaianos: Cook es la historia, Lono es el mito del dios destinado a la muerte. Los mitos pueden morir y convertirse en historia porque se piensan a través de nosotros. Los movimientos quiliásmicos, en efecto, articulan mito e historia. El mito se invierte de sitio puesto que ya no está en el pasado sino en el futuro. En los movimientos de inspiración cristiana se plantea una vuelta al origen, denotando el ascendiente iranio; el mito funciona como algo que está al principio y proyecta una andadura hasta el mito que se repite, es decir, el mito fundador regresa. En los cultos del cargamento se cree en el regreso de los ángeles, así como la ufología se funda en la creencia de que «un día vendrán ellos», los extraterrestres. El comunismo histórico planteó su propia utopía, influenciada por el socialismo utópico de mediados del siglo XIX, en el sentido que se preconizaba que el comunismo primitivo se convertiría en el nuevo mundo socialista y acabaría con las desigualdades creadas por el sistema capitalista. En definitiva, un conjunto de movimientos utópicos se despliegan en el pasado y en el presente con características comunes como el anarquismo, el culto al peyote o «religión del peyote» de los navajo, la «danza de los espíritus» de finales del XIX de los pueblos nativos norteamericanos, las misiones jesuíticas guaraníes fundadas en el siglo XVII, el chiismo, el grupo terrorista ETA, por citar algunos, siendo la lista interminable.

Del mismo modo, existe la utopía del poder, la evolución de la religión hacia el Estado totalitario, el terrorismo de Estado y la religión de Estado. Es el caso de las divinidades que atemorizan en las sociedades clásicas de la Antigüedad, solo invocadas por las castas del orden sacerdotal y que se aplacan solo cuando el pueblo obedece (asociadas al canibalismo, sacrificio, etc.). Esta religión es una utopía negativa, de sumisión y no de liberación pensando que existen relaciones de utopía social liberadora (islam, cristianismo, culto del peyote, culto del cargamento) y de opresión.

En suma, la religión posee una doble lectura: 1) plantea una sociedad perfecta, y 2) propone la superación de la sociedad. Desde el punto de vista religioso, se trata de una superación del orden social, pero también es necesario representar una sociedad ideal al mismo tiempo. Sobre la 
base de ello, la religión no nos habla de una nueva sociedad, sino de una realidad que se puede imaginar. El cristianismo, por ejemplo, admite que existen principios de convivencia (caridad, piedad) que tendrían sentido en su sociedad ideal. Otras religiones como el budismo piensan que no tiene sentido pensar en otra sociedad supraterrenal.

Desde el punto de vista de las ciencias sociales, lo que se analiza es el discurso utópico, la referencia sociológica. Así pues, no es la sociedad sino el reflejo de una sociedad. El propio Bloch interpreta sociológicamente las utopías religiosas de sociedades perfectas. Estas se clasificarían dependiendo del liderazgo social y del Estado. En este caso, hablaríamos de Estados totalitarios, autoritarios y cerrados, los cuales idealizan un orden social y pretenden imponerlo al resto de la sociedad. Es el caso del Egipto faraónico o el Imperio incaico, que poseen una religión de Estado, en la cual los líderes estatales son los sacerdotes de la religión. Es similar el caso de los países liberales o comunistas, que pueden tener utopías sociales (búsqueda de una individualidad más perfecta —liberales-; búsqueda de la solidaridad social — comunistas -) que constituyen ideologías funcionando de manera análoga a la religión.

\section{Aparato ideológico}

En esta perspectiva cuatro autores sobresalen. Marx y su visión determinista; Weber y su idea de compatibilidad; Sombart y Toynbee, quienes discuten sobre cuál religión es más adecuada al poder. El precedente de estos enfoques es Maquiavelo, quien en su obra Discursos sobre la primera década de Tito Livio estudia la historia de Roma y señala que la prosperidad de la República romana, que posteriormente se transformará en imperio, fue acompañada de una religión instituida, pública, de culto participativo y con un conjunto de creencias simples. De ello se sirve para que en su obra más conocida, El príncipe, plantee la idea siguiente: para mantener el orden social se hace necesaria una religión simplista en las creencias, un culto colectivo y que esté de acuerdo con el sistema político. Para Maquiavelo la religión funcionaría como una manera de inculcar comportamientos adecuados al pueblo y congraciarlos, así como como garantía del orden social.

Marx (1975) radicaliza esta idea afirmando que toda manifestación religiosa es un instrumento de una clase social que quiere imponer un orden social sobre otras clases sociales. Como epifenómeno de la base tecnoeconómica, la religión no es más que un mero instrumento más de dominación. Según Marx, el argumento divino es una manera de aceptar cosas inhumanas en nombre de Dios. Así, Marx señala que aquello que los hombres no aceptan en nombre del hombre por ser un abuso de poder o 
una injusticia lo aceptan en nombre de la divinidad. Para Marx, el hombre se sacrifica por un dios, de forma que la religión sería una ideología de sacrificio que predica un grupo de personas para servir a los intereses de una clase social. Por tanto, la religión constituiría un sistema intencionado de interpretar el mundo a través de la alienación puesto que el producto es ajeno a nuestras manos, despersonalizando nuestras funciones. Así, el pensamiento religioso sería una manera de poner fuera de nuestro control elementos creados por nosotros mismos. Siguiendo esta lógica, pareciera que los individuos que están más cerca de su producto es más probable que no desarrollen un pensamiento religioso (por ejemplo, los marineros).

Godelier (1980) lleva hasta sus extremos la idea de la fantasmagoría y la fetichización de la mercancía en Marx al señalar que las representaciones simbólicas se encuentran en la economía y la política, en lugar de la religión. El dominio de la irracionalidad económica se expresaría en la plusvalía simbólica, el valor añadido, del cual estarían investidos los objetos de consumo. Esta sería la plasmación de la alienación del sujeto frente al capitalismo y el punto de convergencia con la religión como fetichización de las relaciones sociales, su valor añadido.

Por su parte, Weber (1984) no habla de determinismo ni de los intereses de clase que determinan la religión. Para Weber la religión es un sistema de creencias, posee cierta economía y, lo más importante, responde a una angustia humana. Lo que ocurre es que, dependiendo de cómo evolucione la religión, convivirá mejor o peor con el orden social, no siendo este el que la determina, como afirmaba Marx. Weber defiende que el protestantismo es la religión que sintoniza mejor con el capitalismo, ya que tiene una ética y una diplomática en la cual: a) la base de toda ceremonia es una relación del hombre individual con Dios, b) refleja una moral del esfuerzo individual y cree en la responsabilidad individual sobre las acciones, c) no hay mediadores entre el hombre y Dios; por ello, los sacerdotes no son importantes en el protestantismo, sino el individuo. Para Weber, el capitalismo requeriría de hombres responsables, independientes y autosuficientes, que no se subordinen a cualquier jerarquía religiosa para que les resuelva los problemas. El catolicismo, en cambio, se orienta a la solidaridad y a la dependencia en una jerarquía. El islam, por su parte, es una religión de masas, cree en sacrificios y actos públicos. Ambos, católicos e islámicos predican la limosna, y son religiones para gente rica o pobre pero no para la gente que trata de enriquecerse, según Weber.

Sombart, en su obra El burgués (1998), señala que el capitalismo era el reino de los usureros y de los financieros, principalmente, los judíos prestamistas. Estos poseían un código de mandamientos fijos, códigos de respeto a la autoridad, una doctrina formal de ritos y protocolos, de 
forma que encajaban a la perfección en el espíritu financiero-burocrático del capitalismo.

Finalmente, Toynbee (1975) afirma que los países capitalistas se ubican cronológicamente: 1) España en el siglo XVI, mayoritariamente católico, 2) Holanda en el XVII se desarrolla después del fracaso de Carlos I, 3) Francia, católico (los hugonotes son minoría), e Inglaterra, anglicano (reforma del catolicismo), en el XVIII, 4) Inglaterra y Estados Unidos (la representatividad oficial en manos de los católicos), en el XIX, y todos ellos en el XX. Para Toynbee, sorprendentemente, el catolicismo resultaría ser la religión más aliada con el capitalismo.

La discusión sobre la dominación ideológica en base a la metáfora arquitectónica de la superestructura/estructura/infraestructura ha sido una tradición fuerte en los estudios de la sociología religiosa. Turner (et al., $1980 ; 1983)$ parte de Marx y Foucault y sus ideas sobre las relaciones económicas y el control disciplinario sobre el cuerpo, para cuestionar la idea que las ideologías dominantes «aplasten» a las clases subordinadas en la sociedad contemporánea. Según Turner, por un lado, las economías modernas no dependen de una clase gobernante ni la posesión y control de los recursos se realiza en base a tales ideologías sino a través de las rutinas del lugar de trabajo y la vida cotidiana — una «jaula de hierro» weberiana materialista- $y$, por otro, la ideología dominante no es incorporada de manera absoluta en la conciencia del trabajador.

Una aspecto clave de la interrelación entre la religión y la política lo constituye los procesos de legitimación religiosa del poder político. Determinadas religiones, como el hinduismo, el budismo y el islamismo, son explícitas a la hora de determinar cuál es el orden político adecuado para sus objetivos religiosos (Smith, 1978). Esto genera situaciones de confrontación y ambivalencia en determinados contextos y coyunturas históricas, como es el caso del Marruecos histórico donde el poder no se ejerce solo a través de la legitimación de la autoridad sino que va de la mano con el empleo de la fuerza bruta (Munson, 1993).

\section{Lubricante social}

Durkheim sitúa la religión entre dos conceptos sociológicos: anomia y altruismo. La idea clave es que para que una sociedad funcione ha de tener gran capacidad de integración. Durkheim (1965) estudia el suicidio y define dos variantes: el suicidio anómico y el altruista. En el primer caso, la sociedad no tiene la capacidad para integrar al individuo ya que no existen reglas, metas ni objetivos fijos. En el segundo, existe gran integración del individuo en la sociedad, de forma que la aceptación mutua es la norma. Ejemplo de ello es el acto heroico de un soldado al arriesgar su vida para 
una actividad aceptada por la sociedad o el suicidio de un asceta religioso. En estos casos, el individuo se encuentra tan absorbido por la sociedad que le puede ocasionar la muerte de forma que para él este tipo de suicidio es aceptable. Durkheim encuentra que aparecen demasiados suicidios entre trabajadores de entre 50 y 60 años, casados y con hijos, suicidios que considera anómicos, puesto que responden al fracaso de la moral dominante: «si trabajas accederás a muchos bienes». Debido a que la experiencia desmintió sus expectativas, la sociedad no lo integraba y de esta forma llegaba la desesperación. Esto se podía evitar haciendo que la religión cumpliera una función complementaria con promesas como «en la otra vida conseguirás tu recompensa», cubriendo la carencia de respuestas éticas de la sociedad. Esto señala un contraste aparente: el poder religioso se ejerce con la amenaza de penas o con promesas, mientras que el poder político se impone a través de la constricción física (armas, monopolio de la violencia). Y, de hecho, si nos referirnos en específico a este poder religioso en relación con una institución religiosa, por ejemplo, la Iglesia católica y en un contexto como el Vaticano, se revela cómo los mecanismos de control no son físicos, pero sí más sutiles pues se emplea el secreto, el espionaje y la represión (la condena a teólogos disidentes), aunque también el poder del Vaticano debe apoyarse en personas laicas para tender puentes entre la jerarquía religiosa y el mundo moderno (Vaillancourt, 1980).

La conclusión es que la religión sería una institución social como cualquier otra: cuando la religión tiene éxito la gente se comporta altruísticamente; cuando la religión no tiene éxito la gente se comporta anómicamente. Desde esta perspectiva, la función de la religión es mantener el equilibrio entre la anomia y el altruismo, o en todo caso servir más al altruismo, a la integración. La religión es cohesionadora porque da al individuo el recurso ideológico y emocional para integrarse a la sociedad. Durkheim no considera a la religión como un instrumento de clase, como algo que se manipula, sino que le otorga una función social: alejar la anomia y evitar una sociedad absurda. Por ello, la religión ha de procurar una moral y hacer que parezca que existe una integración. Si no es así, la sociedad se desintegra. Se infiere que la carencia de integración individual corresponde a una carencia de integración social. No importa de qué religión se trate, lo importante es su función integradora del individuo dentro de la sociedad. Para Durkheim, cualquier sociedad elabora determinadas estrategias que le permiten sobrevivir como tal cultivando una vida social, lo cual implica ventajas y sufrimientos. La sociedad tiende a representar una imagen idealizada de ella misma, y se idealiza a través de la sacralización, de las relaciones que establece con los dioses, con elaboraciones diferentes dependiendo del contexto social y cultural. 
La religión es un discurso que prevé la transcendencia, que tiene que ver con una perplejidad del hombre frente a la vida. Pero en algunas sociedades la ideología económica es la que dicta cómo se han de hacer las cosas, como parece ser el caso de nuestra sociedad, gobernada por principios económicos. Probablemente, el islam es la última religión social o integradora socialmente. Las sectas copian religiones teocráticas y se encuentran dentro de la sociedad de manera parcial, es decir, son marginadas (como el paganismo con Constantino). En este sentido, y siguiendo el enfoque de Durkheim, puede decirse que las sectas son anómicas en referencia a la sociedad y a pesar de que integren a individuos no cumplen una función social, como en el siglo XIII se podía correlacionar el catolicismo con la economía y la política.

En el contexto del mundo laico occidental y contemporáneo la religión, por historia y tradición, es la que proporciona transcendencia e integración en la sociedad, aunque las personas tienden a demostrar más fe en la lotería y en el juego que en la plegaria. En ambos casos se trata de azar y hay fe detrás, lo cual es un hecho religioso construido por la economía. En cualquier caso, Durkheim retoma a Kant, Montesquieu o Rousseau (este último pensador justificaba que la Iglesia, el templo, la liturgia y el dios debían existir, pero al servicio de la razón: el dios es la República), en relación con la necesidad de construir una religión positiva, la cual está basada en las representaciones colectivas: aquello a lo que se rinde culto en las religiones no son los dioses sino la vida social, con lo cual la experiencia de la fe sería descartable. Por tanto, no existiría ninguna creencia o superstición descalificable porque formarían parte de un sistema lógico en el seno de un imaginario y representación colectiva que, a su vez, son lógicos. Desde este punto de vista, el mayo francés del 68 o la revolución mexicana de 1910 podrían observarse como la puesta en escena, como el cristianismo, de la santificación de la comunidad, la parafernalia y la liturgia.

En relación con este último aspecto, Durkheim destaca el ejercicio ritual, la liturgia, el sentido de la ceremonia, como un acto social y, por tanto, como manifestación de la sociedad y, más importante, de la socialidad o sociabilidad. El poder del ritual manifiesta que la vida social debe ser ordenada. Los rituales hablan de la sociedad que los crea, son un paralenguaje, mientras los mitos y el chamanismo constituyen metalenguales.

\section{Mito}

En el campo de la política parece que todo ha de estar ordenado, de modo que estamos más familiarizados con unos órdenes que otros y nos parecen más naturales. No existe demasiada conciencia del orden puesto 
que creemos que este es más eficiente de la manera que se presenta. Esto ha sido investigado en relación con las teorías de la humanidad y la cultura por Lévi-Strauss quien estudia la mitología con hipótesis de orden en el fondo de los mitos. Según esta perspectiva, los mitos reflejarían un poder universal, a la búsqueda del orden original perdido, de igual modo que también lo buscarían formas políticas de orden futuro imbuidas con el perfeccionamiento de la sociedad a través de analogías en la antigüedad (comunismo). En este sentido, Morgan en La sociedad primitiva encuentra en las sociedades romanas el orden sin propiedad, de igual modo que Engels encuentra el orden comunista en las sociedades primitivas.

Aparentemente, el mito imita el orden del cosmos del cual parece conocer su estructura profunda. Por ello, los mitos se muestran análogos al orden del cosmos, cuyas señales son los eclipses, terremotos o sequías. Lévi-Strauss busca el orden en los mitos, de igual forma que la política busca el orden en la sociedad. Pero es la religión, buscando órdenes perdidos, la que aporta toda la imaginación que se requiere. Esta es la razón por la cual la religión se encuentra por encima de la política, incluso está fuera de la sociedad. Para Lévi-Strauss, la religión es más que una creencia; se trata de un fenómeno intelectual y lógico que busca órdenes. En las religiones primitivas se ordena el cosmos de forma integradora: los hombres, los hombres y los dioses, los animales, etc., a diferencia de las religiones monoteístas en las que se ordena a los hombres y a los hombres con respecto a Dios. En uno de sus textos más brillantes (Lévi-Strauss, 1991), el antropólogo francés retoma la teoría sobre el mana (concepto de una fuerza o cualidad impersonal que poseen las personas, animales y objetos inanimados entre los nativos de Polinesia, Melanesia y Micronesia) de Mauss señalando que responde a la necesidad de crear un significado flotante que aparece allí donde se encuentra el vacío, el cual el pensamiento se niega a reconocer y, por ello, coloca el poder. El mana, aquello que hace a los objetos poderosos y que debe ser domesticado a través de la eficacia ritual, sería un precursor de la religión formal. Lévi-Strauss, con ello, plantea que esta teoría hace comprensibles los fenómenos religiosos y políticos partiendo de la definición del mana como comodín, poder informe y, a la vez, fonema y valor simbólico «cero», a lo Jakobson, en términos de la lingüística. Así, la función simbólica se asemeja a la función poética. En suma, un ejemplo de elemento ordenador del cosmos. Ello refleja una línea de continuidad que va de Mauss a Durkheim pasando por Saussure hasta llegar a Lévi-Strauss, en el sentido de que lo que cuenta en última instancia es la necesidad de reconstruir las leyes gramaticales frente al supuesto de que la historia explica alguna cosa. En el fondo, estos autores se levantan contra una explicación diacrónica y horizontal del mundo, y la 
religión comparada en Max Müller. Este señalaba que el lenguaje fue otorgado al ser humano y así se dedicó a hablar con un exceso de significados hasta el momento que decayó al no poder controlar ese exceso. Los evolucionistas señalaban que el mito reflejaba una serie de cultos inefables que demostraban la incapacidad de pensar del hombre primitivo. Durkheim, Mauss, Hubert, Hertz, Hocart, por un lado, Jakobson, Propp y Saussure, por otro, siguiendo con Soustelle, Leenhardt, Griaule, Granet, con Dumézil en medio, hasta llegar a Lévi-Strauss, muestran la vitalidad de la tradición francesa estructuralista en relación con el estudio de la mitología y la estructura del espíritu humano desde un punto de vista intelectualista y especulativo, a diferencia del enfoque pragmático, centrado en los rituales, de la escuela inglesa que proviene de Pierce, continúa con Whitehead y desemboca en el estructural-funcionalismo y la antropología simbólica. En esta tradición inglesa no aparece la cuestión de la religión o la magia dado que se privilegia el estudio del ritual en función de las necesidades de una sociedad determinada y una cultura en términos de la estructura social, con lo cual se refleja un enfoque de sociología comparada. En cambio, para Lévi-Strauss el pensamiento «salvaje», el lenguaje metalingüístico, crea tres formas para hacer frente al exceso de significantes: el totemismo (formas de clasificación), la magia (eficacia simbólica del chamanismo) y la mitología (forma de pensamiento), de forma que el ritual no pertenece a las actuaciones del pensamiento salvaje sino de forma parcial al igual que la religión, la cual Lévi-Strauss no teoriza. Si para Durkheim es lo sagrado lo que determina lo ritual, para Radcliffe-Brown es la práctica ritual lo que convierte en sagrado a individuos, objetos y lugares.

Sin embargo, la política extravía estas relaciones de orden y a lo sumo intentaría copiar estos órdenes religiosos, en los cuales la divinidad sería el ser que conoce y se confunde con un orden más perfecto. Por tanto, el mito busca e impone órdenes y extrae de la imaginación los órdenes más perfectos de la religión. En el cristianismo, la Biblia aporta solo una escasa referencia en el Génesis, el resto del relato se centra en una relación moral entre personas, así como entre personas y Dios. En las religiones primitivas, aparecen variaciones de este Génesis, descartando o minimizando el orden social. La diferencia estriba en que en la Biblia no se discute, sino que existe una verdad revelada, un orden no conscientemente codificado: Dios informa quiénes son los padres, cómo se ha de poblar la Tierra, etc.

En las Mitológicas de Lévi-Strauss aparecen una serie de secuencias y frases míticas en referencia a órdenes básicos. No se trata de una utopía social sino de órdenes cósmicos que muestran universos diferentes (sol, cielo, estrellas, mar, etc.). En Freud esa vuelta atrás es el instinto, la búsqueda de cualquier estado previo del organismo; este argumento biologista 
sostiene que el instinto no es la búsqueda de algo que no existe, sino de un estado anterior, ya sea el estado de la infancia, el aprendizaje, la satisfacción y el equilibrio del que se ha gozado antes.

En este sentido, para Lévi-Strauss la función de los mitos y rituales sería restituir un estado previo, el orden básico perdido, la máxima perfección y saturación. Referirse a tiempos pasados, sobre todo entre los pueblos primitivos, indica una búsqueda intelectual de un orden perdido. Los temas míticos con frecuencia aluden a una incomunicación entre los animales y el hombre — quienes han aprendido a alimentarse-, el hábitat y las costumbres de los animales, pero no pueden controlar la naturaleza o el clima (los secretos del clima, los accidentes geográficos, etc.). La utopía subyacente consiste en que el hombre conocía el orden de la naturaleza en el pasado. En síntesis, la oposición sería, llegados a este punto, entre la divinidad, la cual articula los lenguajes del cosmos, y la política, que vendría a ser la religión de los hombres. Por un lado, dominio del cosmos, por el otro, dominio de la sociedad.

Una de las ideas más significativas del estructuralismo leviestraussiano es que no siempre lo que tiene mayor religiosidad produce angustia. Un peligro o un viaje también la generan. El objetivo de los seres humanos es tratar de entender el universo que les rodea, y por ello, la función de la religión sería disminuir la tensión y la angustia en la medida que se entiende y se comprende la realidad. Para Lévi-Strauss cualquier cultura es un sistema para decodificar mensajes y cualquier sistema de creencias funciona para introducir coherencia en la vida social en relación con la naturaleza. Un sistema religioso, por tanto, se valoraría porque brinda una macrovisión de las relaciones con el mundo.

Otros autores como Hertz (1990) exploran la representación colectiva de la muerte y la preeminencia de la mano derecha como polaridad religiosa en varias culturas. En el primer caso, señala que la muerte es, con frecuencia, culturalmente ocultada pues depende de los sistemas de representación que la conciben como contaminable. Así, el periodo del luto cumpliría una función estructural puesto que el muerto se integra en otra sociedad y no se tiene clasificado el proceso de putrefacción, el cual es un estadio impuro. Así, el pariente — de luto- se sitúa en un estado misto. En el caso de la dominancia de la mano derecha se retoma la idea de polaridad que recuerda al dualismo lévistraussiano en el sentido de que el ser humano piensa en dos mitades, con la parte izquierda del cerebro porque escribe con la mano derecha, lo cual tiene un fundamento religioso.

En definitiva, la religión cumple la función de racionalizar el medio. Aquello que la diferencia es que su explicación se propone como verdad 
inmutable (el cambio de una religión a otra es un «cisma»), mientras la explicación científica está sujeta a cambios y nuevas teorías.

\section{Chamanismo}

Básicamente la discusión en torno al chamanismo ${ }^{3}$ como problema gravita en relación con dos posiciones: 1) los chamanes poseen naturaleza política, 2) los chamanes no poseen naturaleza política. Si la opción 1 es cierta, hablaríamos del chamán como parte de una autoridad carismática que no está instituida ni es permanente sino espontánea, inconsciente, amorfa y muy vinculada a la propia personalidad del individuo. Si se acepta la opción 2, hablaríamos de unas relaciones políticas subyacentes en el rol del chamán en la sociedad y la cultura.

Chamán proviene de lenguas indoeuropeas y limítrofes de algunos pueblos del Asia Central y Oriental. Etimológicamente, significa una persona que ve más de lo normal. En concreto, el término procede de las lenguas de la Siberia Central y designa unas funciones similares en otras culturas, aunque en sentido estricto el chamanismo solo se encuentra entre los Tunguses siendo realizado por mujeres primordialmente. Entre los Tunguses existe la creencia de que por naturaleza la mujer es ya una chamana, puesto que puede hablar de las cosas que están por encima y por debajo de la tierra y del tiempo, pasado y futuro. Para nosotros, las finalidades parecen ser el curanderismo, las profecías, los rituales o la adivinación. Las funciones de este chamanismo original se reducirían a dos: 1) profética: el chamán ve y las mujeres ven aquello que los hombres no ven. Algunos etnólogos atribuyen el comportamiento afeminado de los chamanes a que es la mujer la visionaria. Esta función profética es la más importante, pero nos ha llegado oralmente, por tanto, imperfecta; y 2) sacerdotal: el chamán dirige actos y rituales religiosos, sobre todo, colectivos, sacrificales e iniciáticos.

Formalmente, el chamán opera expresándose con cantos, música, mimo, dramatiza situaciones, imita a los muertos y a los vivos, a los animales, habla con diferentes timbres de voz, cuida mucho el gesto. La representación puede ser colectiva, pero el líder es el chamán. La cultura chamánica es una mezcla de cultura médica, intelectual, artística y religiosa. El chamán pinta, hace máscaras, disfraces, diseña altares, inventa palabras y, además, cura. Aquello que impresiona a un observador foráneo es, sin duda, sus relatos y su teatro como intermediarios entre los espíritus

3 El término chamanismo es convencional, pues deriva de los trabajos de Eliade, muy influido por la idea de posesión y de éxtasis, pero no puede dar causa de las diferentes prácticas locales en diversas culturas. 
y el mundo de los humanos. Estos pueblos poseen una mitología cósmi$\mathrm{ca}$, puesto que existen planos celestiales, cada uno con sus divinidades y espíritus, siendo así que cada plano superior tiene más perfección y se aleja más de la Tierra. Para el occidental, el chamán está a medio camino de todo, de la música, de la danza. A veces fuma o bebe para intoxicarse ayudándole a su tarea; sin embargo, las mujeres siberianas señalan que no necesitan drogas mientras los hombres imitan a las mujeres y necesitan estímulos. En suma, el chamanismo tiene que ver con un campo cultural que no poseemos y lo relacionamos con aquello propio que se acerca más: puede ser religión, puede ser medicina, puede ser política, puede ser arte.

Para algunos etnólogos, el chamanisno no posee funciones políticas señalando que las ceremonias del chamán son de iniciación. Las ceremonias colectivas más conocidas eran los sacrificios de animales (en Siberia los caballos) y ceremonias de iniciación, y en ocasiones, para sanar la enfermedad de las personas. La interpretación a todo esto se decanta hacia la cuestión de la terapia psicológica, la estimulación de la vivencia colectiva de los fenómenos, la idea del viaje, de recorrer diversos ambientes y franquear obstáculos. En este caso, el chamanismo sería conceptuado como una catarsis, una representación teatral sin relación con la política.

El chamanismo muestra que existe un lugar donde todo está apabuIlantemente claro para el ser humano, donde la razón y las distinciones no se han producido todavía. Ello sería el reflejo de la creatividad del espíritu humano. En este caso, el pensamiento irracional no existe, siendo el chamán el sujeto más racionalista que otro pues hace la razón ejecutiva. El chamanismo y la magia, en efecto, representarían la capacidad del ser humano de ir más allá de lo tangible, lo material, lo físico y empírico. Esta razón habría existido desde los primeros Homo sapiens, al representar una exigencia del ser humano para que el universo signifique. El surrealismo occidental se acercaría a este terreno donde se expulsa el yo, un ser en sí, pero sin esencia, para llegar al vacío, allí donde están el pensamiento y los monstruos, el más allá aquí en el mundo, no alterando la conciencia sino relegándola. El surrealismo se conectaría con el chamanismo en la medida que la conciencia es un invento y un producto histórico de la reforma protestante que inventa la interiorización del yo, el sujeto como fetiche, como si existiera un vigilante dentro de nuestra mente que permite discernir el bien del mal.

La relación de la religión con la política puede argumentarse de otro modo. De entrada, podemos pensar que existe un acto religioso fundamental: el ritual de iniciación. Van Gennep (1986) explora los ritos de paso en las sociedades occidentales y entre los pueblos primitivos, cuyo 
derecho no está escrito. Dichos ritos de paso tienen que ver con tránsitos en la vida de la persona. El más importante es el de la pubertad que consiste en la integración en el mundo de los adultos. Algunos antropólogos piensan que las sociedades se han definido socialmente por los rituales de iniciación. Por ejemplo, la educación, la escuela, el servicio militar y otro tipo de rituales complementarios para acceder a otros campos de la vida social. Los antropólogos norteamericanos piensan que el hombre reproduce los rituales de iniciación en la época adulta como la jubilación o el desempleo, lo que para los antropólogos británicos —en la línea de Víctor Turner - representa una serie de rupturas dramáticas, es decir, una experiencia fuerte, estresante. Para otro, los rituales de iniciación son el origen de la política en el sentido de que una comunidad adulta decide una serie de disciplinas para imponer a los demás y conseguir la integración social. Cabe recordar que los rituales de iniciación poseen componentes como una división política, ya que aparecen los conductores y los concurrentes.

Habitualmente, la iniciación nunca explica objetivamente y de manera clara en qué consiste el ritual y hasta dónde llega, puesto que hay unos valores implícitos que otorgan un misterio. El ritual de iniciación posee tres funciones simbólicas: 1 ) la revelación: una parte de los misterios son revelados, 2) el misterio, y 3) una forma de comportamiento para antes y después del ritual. El ritual de la pubertad en Australia, por ejemplo, posee una serie de disciplinas definidas por el propio ritual, un comportamiento a veces terrorífico. El miedo es muy importante en los rituales de iniciación debido a que se hace sentir miedo para cambiar la mentalidad y el comportamiento, y en donde la recuperación será difícil por su carácter estresante y el sufrimiento. La experiencia iniciática es muy importante en los pueblos primitivos puesto que tiene que ver con la inculcación del orden social y lo importante es recordar o reproducir constantemente el ritual de iniciación (existen conmemoraciones como en nuestra sociedad). Con ello, se acepta una forma de vida después de esta experiencia y se consolida.

Además, otro componente del ritual de iniciación es el sacrificio. La política demanda sacrificio y la religión ofrece sacrificio. La experiencia de la iniciación es un sacrificio puesto que el iniciado sufre y tiene miedo. Simbólicamente, los seres humanos padecen los mismos sacrificios que los no humanos. El sacrificio comporta una utilidad (los que mandan) y una inutilidad (los que sufren pueden estar de acuerdo o no). La idea de sacrificio es la idea de un ritual de iniciación útil y bajo un consenso. En la mayoría de sociedades primitivas aparecen actos sacrificales, pero no existe una ideología sacrifical. En resumen, en un pueblo primitivo la integración social no se entiende sin un ritual de iniciación y sus continuidades. 
Así pues, la alianza más elemental entre religión y política viene dada por el ritual de iniciación.

\section{A modo de conclusión}

El poder posee diversas dimensiones. Podemos abordarlo, entre muchas y variadas perspectivas, desde la crítica del poder a nivel histórico, desde la antropología política, desde la representación y los disfraces, desde una arqueología a lo Foucault o desde su articulación con la religión. Mientras haya poder habrá historia puesto que la historia nace con el poder. El proceso histórico-social está constituido primero por personas, y segundo, por las relaciones entre personas. Las ciencias sociales estudian las relaciones entre personas y sus instituciones. Por otro lado, existen varias metodologías y marcos teóricos en el estudio de la religión como el cognitivismo, la fenomenología, la hermenéutica o el subjetivismo del actor que se proponen para su abordaje desde diferentes ángulos.

La cuestión es que los problemas teóricos sobre la imbricación entre religión y poder se encuentran lejos de estar resueltos. Mi planteamiento aquí ha resultado más bien modesto y se ha basado en repensar seis concepciones de la religión estrechamente imbricadas con el poder. No fue mi intención abstraer un modelo analítico de lo que la religión «es» al precio de sustancializar un universo de creencias, prácticas e instituciones que pertenecen a contextos históricos y culturales particulares, sino más bien explorar, sin ánimo de exhaustividad, algunas dimensiones que me parecen significativas y que imbrican a la religión con el poder y viceversa. 


\section{REFERENCIAS BIBLIOGRÁFICAS}

Asad, T. (1993). Genealogies of Religion. Discipline and Reasons of Power in Christianity and Islam. Baltimore: Johns Hopkins.

Bloch, E. (1979). El principio de la esperanza. Madrid: Aguilar.

De Coulanges, F. (1983). La ciudad antigua. Estudio sobre el culto, el derecho y las tradiciones de Grecia y Roma. México D.F.: Porrúa.

Dumont, L. (1970). Religion, Politics, and Society in the Individualistic Universe. Proceedings of the Royal Anthropological Institute of Great Britain and Ireland, 1970, pp. 31-41.

Durkheim, E. (1965). El suicidio. Estudio de sociología. Buenos Aires: Shapire. Godelier, M. (1980). Economía, fetichismo y religión en las sociedades primitivas. México D.F.: Siglo XXI.

Hertz, R. (1990). La muerte y la mano derecha. Madrid: Alianza Editorial.

Lévi-Strauss, C. (1969). Las estructuras elementales del parentesco. Buenos Aires: Paidós.

Marx, K. (1975). La ideología alemana. Buenos Aires: Ediciones Pueblos Unidos.

Munson, H. (1993). Religion and Power in Morocco. New Haven: Yale University Press.

Sahlins, M. (1988). Islas de historia. Barcelona: Gedisa.

Smith, B. (edited by) (1978). Religion and the Legitimation of Power in South Asia. Leiden: E. J. Brill.

Sombart, W. (1998). El burgués. Contribución a la historia espiritual del hombre económico moderno. Madrid: Alianza Editorial.

Tarrius, A. (2000). Les nouveaux cosmopolitismes. Mobilités, identités, territoires. París: L'Aube.

Toynbee, A. (1975). Estudio de la Historia. Madrid: Alianza Editorial.

Turner, B., Abercrombie, N., Hill, S. (1980). The Dominant Ideology Thesis. Londres: G. Allen \& Unwin.

Turner, B. (1983). Religion and Social Theory. A Materialist Perspective. Londres: Heinemann.

Vaillancourt, J. G. (1980). Papal Power. A Study of Vatican Control over Lay Catholic Elites. Berkeley: University of California Press.

Gennep, A. van (1986). Los ritos de paso. Madrid: Taurus.

Weber, M. (1984). La ética protestante y el espíritu del capitalismo. Madrid: Península. 
Wittgenstein, L. (1992). Observaciones a La Rama Dorada de Frazer. Madrid: Tecnos.

Worsley, P. (1980). Al son de la trompeta final. Estudio de cultos «cargo» en Melanesia. Madrid: Siglo XXI.

Zulaika, J. (1992). Caza, símbolo y eros. Madrid: Nerea.

Recibido: junio de 2016 Aceptado: diciembre de 2016 